\title{
Estudo de Acoplamento Molecular e NBO das Interações entre a Molécula 5-FU e o Alvo Biológico HER-2
}

\author{
Michell O. Almeida, Daiane A. S. Barros, Sheila C. Araújo, \\ Sergio H. D. M. Faria \& Kathia Maria Honório
}

\section{Introdução}

$\mathrm{O}$ câncer é uma doença que atualmente afeta grande parte da população. Essa doença crônica tem como características a proliferação e o crescimento celular rápido e descontrolado. A cada ano, o número de casos de câncer aumenta e devido a este fato, diversos estudos vêm sendo realizados com o intuito de tratar o câncer ${ }^{1}$. Alguns estudos mostram que existem diversos alvos biológicos relacionados a essa enfermidade. Um desses alvos é o receptor tipo 2 do fator de crescimento epidérmico humano (HER-2), sendo que a amplificação do gene faz com que haja produção excessiva da proteína contribuindo, assim, para a progressão do câncer ${ }^{2}$. Desta forma, busca-se inibir essa proteína. Uma molécula utilizada em estudos sobre o câncer é a 5-FU (5-fluorouracil)3. Desta forma, neste trabalho foram utilizados os seguintes métodos computacionais: acoplamento molecular, cálculos quânticos em meio solvatado (para validar os métodos teóricos) e cálculos $\mathrm{NBO}^{4}$ (orbitais naturais de ligação), tendo como objetivo estudar as possíveis interações que ocorrem entre a molécula 5-FU e sítio ativo de HER-2.

\section{Método}

$\mathrm{O}$ acoplamento molecular foi realizado utilizando o programa GOLD, tendo como intuito inserir a molécula 5-FU no sítio ativo de HER-2 (PDB 3PP0) e analisar as interações intermoleculares entre 5-FU e HER-2. Após a análise do acoplamento, foram realizados cálculos da molécula 5-FU em solvente dioxano (métodos IEFPCM e Osanger), pois a comparação dos valores dos momentos de dipolo teóricos e experimentais $\left(4,11 \pm 0,5\right.$ Debeye, $\left.\mathrm{D}^{5}\right)$ é utilizada para escolher e validar as funções de bases a serem selecionadas (B3LYP/6-31G (2d,2p) e B3LYP/cc-pVDZ) para o cálculo dos orbitais naturais de ligação (NBO). O cálculo NBO teve $\mathrm{o}$ intuito de analisar as interações de orbitais aceptores e doadores da molécula 5-FU e dos resíduos ASP-863 e PHE864 (resíduos que fazem interações de ligação de hidrogênio com 5-FU, mostradas pelo acoplamento molecular).

\section{Resultados e Discussão}

A Figura 1ilustra a interação intermolecular (ligação de hidrogênio) entre 5-FU e o sítio ativo de HER-2 (resíduos ASP-863 e PHE-864).

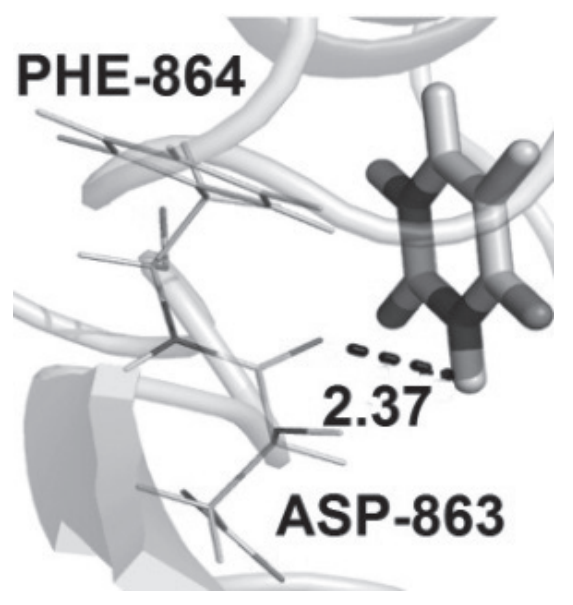

Figura 1. Análise do acoplamento molecular da estrutura 5-FU no sítio ativo de HER-2 (PDB 3PP0). 
Após as análises do acoplamento, foram realizadas comparações dos valores de momento de dipolo teórico e experimental (Tabela 1).

Tabela 1. Valores teóricos de momento de dipolo para 5-FU em solvente dioxano, comparados com o valor experimental (4,11 $\pm 0,5 \mathrm{D})$

\begin{tabular}{|c|c|c|}
\hline B3LYP & PCM & Osanger \\
\hline 6-31G(2,2p) & 4,35 & 4,17 \\
\hline cc-pVDZ & 4,35 & 4,15 \\
\hline
\end{tabular}

Os resultados mostram que ambas as funções de base são válidas para cálculos computacionais, sendo que a próxima etapa foi a realização da análise $\mathrm{NBO}$, que se encontra na Figura 2 e Tabela 2.

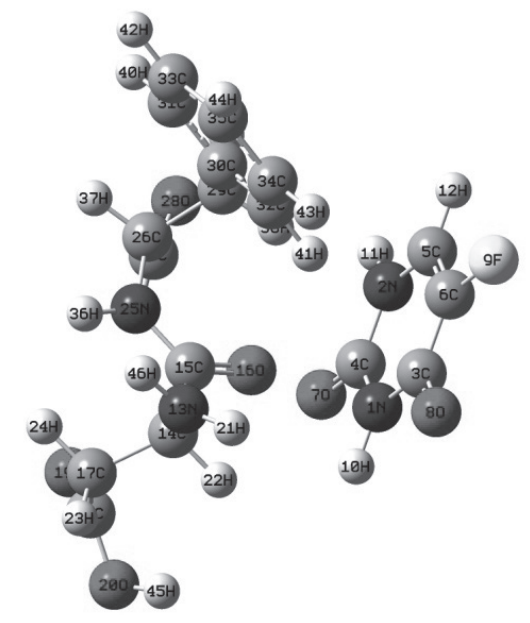

Figura 2. Estruturas de 5-FU, ASP-863 e PHE-864 utilizadas na análise NBO.

Tabela 2. Análise NBO para a molécula 5-FU*

\begin{tabular}{|c|c|c|c|}
\hline \multicolumn{4}{|c|}{ NBO Doador NB0 Aceitador $\Delta \mathbf{E}^{2}(\mathbf{k c a l} / \mathbf{m o l})$} \\
\hline \multicolumn{4}{|c|}{ 5-FU para ASP-863 e PHE-864 } \\
\hline LP N1 & RY* 016 & 0,84 & cc-pVDZ \\
\hline LP N1 & RY* 016 & 1,17 & 6-31G(2d,2p) \\
\hline \multicolumn{4}{|c|}{ ASP-863 e PHE-864 para 5-FU } \\
\hline LP 016 & BD* $(\pi)$ C3-09 & 5,43 & cc-pVDZ \\
\hline LP 016 & BD* $(\pi)$ C3-09 & 4,47 & 6-31G(2d,2p) \\
\hline
\end{tabular}

*BD (Ligante), BD* (Anti-ligante), LP (Lone Pair, par solitário) e RY* (Rydberg anti-ligante).
A Tabela 2 apresenta as interações de transições eletrônicas que ocorrem entre os orbitais aceptores e doadores NBO de 5-FU e dos resíduos ASP-863 e PHE864 e também mostra o valor da energia perturbativa de segunda ordem, a qual estabiliza esse sistema doadoraceitador. Nota-se que para ambas as funções de base, o maior valor de transição eletrônica que ocorre é entre os resíduos ASP-863 e a molécula 5-FU. Sendo assim, os resultados apresentados sugerem uma transferência do par de elétrons do átomo O16 para os orbitais antiligantes $\mathrm{BD}^{*}(\pi) \mathrm{C} 4-\mathrm{O} 7$, indicando um mecanismo de reação entre ASP-863 e 5-FU.

\section{Conclusões}

Os métodos empregados neste estudo de modelagem molecular, tais como cálculo teórico da molécula 5-FU em solvente, acoplamento molecular e a análise dos orbitais de naturais de ligação (NBO), fornecem dados significativos para o planejamento de novas substâncias, candidatas ao tratamento do câncer. Os resultados obtidos no acoplamento molecular indicam possíveis interações que podem ocorre entre o composto 5-FU e resíduos do sítio ativo de HER-2, onde se notou que o composto interage com o resíduo de aminoácido ASP-863. Os resultados obtidos dos cálculos de 5-FU em solvente se mostraram próximos dos valores experimentais, sendo que os métodos escolhidos para o cálculo NBO são válidos. Por fim, os resultados obtidos pela técnica NBO foram capazes de indicar a interação intermolecular que ocorre entre os orbitais aceptores e doadores de elétrons do composto 5-FU e dos resíduos de aminoácido ASP863 e PHE-864, sendo que essas informações são de extrema importância no estudo das interações desses compostos com o sítio ativo de HER-2.

\section{Agradecimentos}

Os autores são gratos pelo apoio dado pela FAPESP, UFABC, CAPES e CNPq.

\section{Referências}

1. T. L. Lemke, D. A. Williams, V. F. Roche, S. W. Zito. Foye's principles of medicinal chemistry. 6 ed.; Lippincott Williams \& Wilkins (2008).

2. I. Kümler, M. K. Tuxen, D. L. Nielsen.Cancer Treat. Rev, 40 (2), 259, (2014). 


\section{Artigo Geral 40}

3. E. T. H. Yeh, C. L. Bickford. J. Am. Coll. Cardiol, 53 (24), 2231, (2009).

4. J. P. Foster, F. Weinhold, J. Am. Chem. Soc, 102, 7211, (1980).

5. I. Kulakowska, M. Geller, B. Lesyng, K. L. Wierzchowski. Dipole moments of 2,4-diketopyrimidines: Biochim. Biophys. Acta, 361 (2), 119 (1974).

\section{Michell O. Almeida ${ }^{\text {, Daiane }}$ A. S. Barros ${ }^{b}$, Sheila C. Araújo ${ }^{\prime}$ Sergio H. D. M. Faria $^{\mathrm{c}, \mathrm{d}}$ \& Kathia Maria Honório $^{a, b}$}

${ }^{\mathrm{a} C e n t r o ~ d e ~ C i e ̂ n c i a s ~ N a t u r a i s ~ e ~ H u m a n a s ~-~ U F A B C ~}$

${ }^{\text {b} E s c o l a ~ d e ~ A r t e s, ~ C i e ̂ n c i a s ~ e ~ H u m a n i d a d e s ~-~ U S P ~}$

c Instituto de Química, Universidade Estadual de Campinas

${ }^{\text {d} I n s t i t u t o ~ d e ~ C i e ̂ n c i a s ~ d a ~ S a u ́ d e, ~ U n i v e r s i d a d e ~ P a u l i s t a, ~ C a m p i n a s-S P ~}$ 